
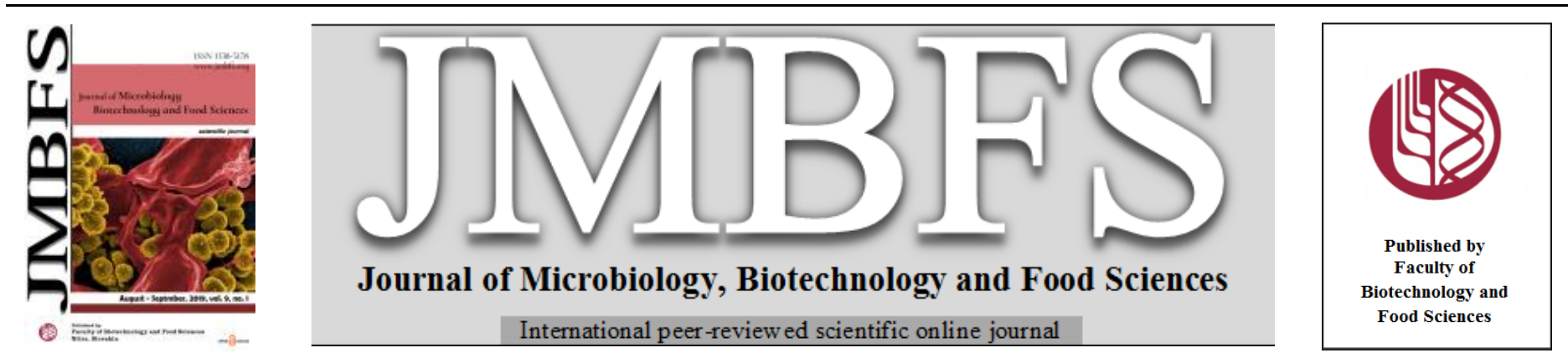

\title{
FEMORAL GLAND SECRETION OF GEKKONIDS HEMIDACTYLUS AQUILONIUS AND HEMIDACTYLUS FLAVIVIRIDIS FROM ASSAM, INDIA
}

\author{
Madhurima Das ${ }^{1,2}$, Madan G. Borthakur ${ }^{3}$, Shubhadeep Roychoudhury* ${ }^{4}$, Bhim B. Biswa ${ }^{2}$, Jayaditya Purkayastha ${ }^{1,2}$
}

Address(es): Dr. Madhurima Das, PhD.,

${ }^{1}$ Department of Zoology, Gauhati University, Guwahati 781014, Assam, India, Phone number: +91-9864753929.

${ }^{2}$ Help Earth, Guwahati 781007, Assam, India.

${ }^{3}$ Guwahati Biotech Park, Technology Complex, IIT Guwahati, Guwahati 781039, Assam, India.

${ }^{4}$ Department of Life Science and Bioinformatics, Assam University, Silchar 788011, India.

*Corresponding author: madhuherp@gmail.com, shubhadeep1@gmail.com

doi: 10.15414/jmbfs.2019.9.1.156-159

ARTICLE INFO

Received 12. 4. 2019

Revised 24. 6. 2019

Accepted 24. 6. 2019

Published 1. 8. 2019

Regular article

OPEN $\partial_{\text {ACCESS }}$

\begin{abstract}
Lizards have been around since the time of the dinosaurs, but climate change poses a threat to their existence on earth as they are highly sensitive to temperature fluctuations. They feed on nocturnal insects and occasionally are cannibalistic, eat rice grain, appreciate sugar, and at times seeds of wild plants and rarely hibiscus flowers. The present study reports the femoral gland secretion of two species of Gekkonids Hemidactylus aquilonius and Hemidactylus flaviviridis from Assam using gas chromatography and mass spectrometry techniques. In Hemidactylus aquilonius esters (35\%) and alkanes (25\%) were predominant whereas alkanes (53\%), esters (21\%) and halides $(11 \%)$ were the major constituents of femoral gland secretion of Hemidactylus flaviviridis. In conclusion, this is the first report on the femoral gland secretion from the genus Hemidactylus in Assam.
\end{abstract}

Keywords: house gecko, Hemidactylus aquilonius, Hemidactylus flaviviridis, femoral gland secretion, alkanes, esters

\section{INTRODUCTION}

Chemoreception is an important characteristic in lizards. The males usually possess the precloacal femoral glands on the ventral surface. These glands are epidermal structures present on the ventral surface of the thighs which secrete chemical cues (Smith, 1935). Their location suggests that the secretion is usually deposited on a substratum as the lizard moves about. These cues may be the implication of home range, social status or competitive ability of the male or information on the quality of male for mating choice by the female (Martın and Lopez, 2000; Aragon et al., 2001; Lopez and Martin, 2002). The secretions of these glands are usually certain organic compounds or pheromones. Analysis of secretion of femoral glands in lizards such as Lacertids and Iguanids (Chauhan, 1986; Alberts, 1990; Weldon et al., 1990; Alberts et al., 1992; Escobar et al., 2001, 2003; Lopez and Martin, 2005) suggested the presence of lipids, carboxylic acids and alcohols. Despite their immense importance in territory making by the males of the species as well as attracting females during mating, studies on the femoral gland secretion of most lizards have not been carried out so far.

The genus Hemidactylus or house geckos occupy a wide range of habitats ranging from household walls to tree barks to leaf litters. From the Indian northeastern state of Assam, five species of these geckos have been described. Although taxonomic studies and the bioinventory have been carried out (Purkayastha et al., 2011), studies related to components of femoral gland secretion of lizards is lacking from this region. Hence, the aim of the present work was to study the pre-anal femoral gland secretion of two species of house geckos Hemidactylus aquilonius and Hemidactylus flaviviridis from Assam.

\section{MATERIAL AND METHODS}

\section{Sample collection}

H. aquilonius and H. flaviviridis males were captured by hand during the months of July till October, 2014 (figure 1). The lizards were weighed, their body length measured and the femoral pore number was counted. After capture, secretions from femoral glands of the male

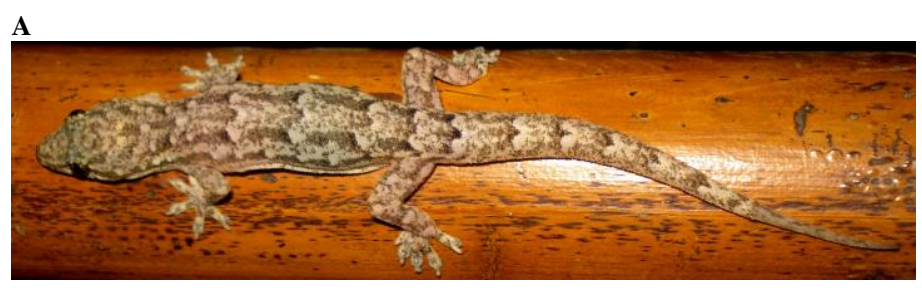

B

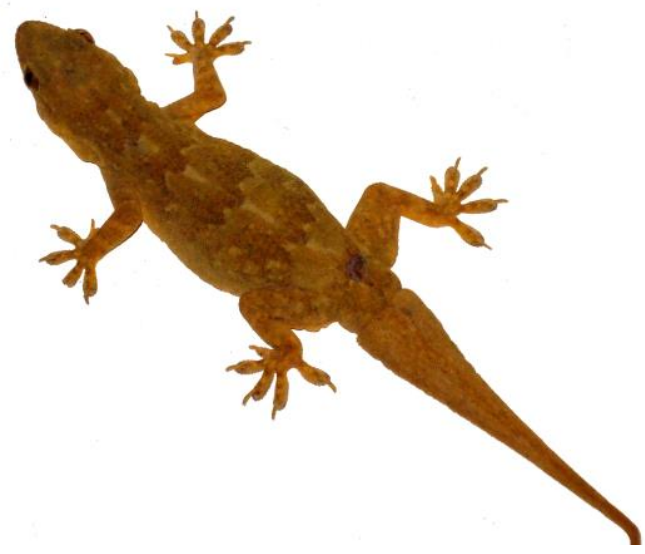

Figure 1 Two species of house geckos in the present study (A) Hemidactylus aquilonius and (B) Hemidactylus flaviviridis.

Lizards were extracted by gently pressing around the femoral pores with forceps, and the secretion was directly collected into glass vials followed by closure with teflon-lined stoppers. The vials were stored at $-20^{\circ} \mathrm{C}$ until further analysis. The lizards were then immediately released to their capture sites. 


\section{Gas chromatography/mass spectrometry}

Samples were analyzed using Perkin Elmer make Claurus 680 Gas Chromatograph and Claurus 600C Mass spectrometer. Elite-5MS capillary column (length $60 \mathrm{~m}$, ID $0.25 \mathrm{~mm}$, maximum program temperature $350^{\circ} \mathrm{C}$ ) was used with phase reference of 5\% diphenyl and 95\% dimethyl polysiloxane (low bleed). $5 \mu \mathrm{l}$ of sample was dissolved in $10 \mathrm{ml}$ of HPLC grade $\mathrm{n}$-hexane and injected in 0:1 splitless mode. The gas chromatograph was programmed to an initial oven temperature of $50^{\circ} \mathrm{C}$ for 10 minutes, increased to a final temperature of $280^{\circ} \mathrm{C}$ at the rate of $8^{\circ} \mathrm{C}$ per minute and kept for 10 mins. The carrier gas used was helium. The injector temperature was $250^{\circ} \mathrm{C}$. Impurities identified in the solvent and/or the control vial samples were not reported. The relative amount of each component was determined by the total ion current (TIC). Library search was carried out against the most relevant peaks.

\section{RESULTS AND DISCUSSION}

Gas chromatography/mass spectrometry analyses of the femoral gland secretions of male house geckos $H$. aquilonius and $H$. flaviviridis gave total ion chromatograms that were qualitatively as well as quantitatively different (figure 2). A total of 35 compounds were identified from the femoral gland secretion of the house geckos, 16 from $H$. aquilonius 19 from $H$. flaviviridis. In $H$. aquilonius the highest retention time was showed by the compound dichloroacetic acid, 2,2dimethylpropyl ester followed by hexacosane; cyclohexane, 1,1'-[1,2-bis $(1,1-$ dimethylethyl)-1,2-ethanediyl]bis-, $\quad\left(\mathrm{r}^{*}, \mathrm{r}^{*}\right)-(. ; \quad \mathrm{D}-\mathrm{mannitol,} \quad$ 1-o-(22hydroxydocosyl)-; and sulfurous acid, butyl heptadecyl ester (Table 1). In $H$. flaviviridis the compounds such as sulfurous acid, butyl tetradecyl ester demonstrated the highest retention time followed by ; hexacosanol, acetate; pentatriacontane; octatriacontane, 1,38-dibromo-; and heptacosanoic acid, 25methyl-, methyl ester thereby confirming their absolute presence followed (Table 2).

Table 1 Individual constituents present in the femoral gland secretion from the house gecko Hemidactylus aquilonius

\begin{tabular}{c|l|c|c}
\hline Sl. No. & \multicolumn{1}{|c|}{ Constituent } & $\begin{array}{c}\text { Retention time } \\
\text { (minutes) }\end{array}$ & $\begin{array}{c}\text { Molecular } \\
\text { weight }\end{array}$ \\
\hline 1 & 2-propenoic acid, methyl ester & 21.76 & 86 \\
\hline 2 & 1-butene-3-ethoxy & 22.34 & 100 \\
\hline 3 & Cyclobutanecarboxylic acid, pent-2-en-4-ynyl ester & 23.61 & 164 \\
\hline 4 & Oxalic acid, cyclobutyl pentadecyl ester & 35.58 & 354 \\
\hline 5. & Octadecane, 1-chloro- & 36.83 & 288 \\
\hline 6 & 1-dodecanol, 2-methyl-, (s)- & 37.05 & 200 \\
\hline 7 & Heptadecane, 2,6,10,15-tetramethyl- & 38.43 & 296 \\
\hline 8 & Methyl 2-hydroxy-eicosanoate & 38.54 & 342 \\
\hline 9 & Docosanoic acid, docosyl ester & 39.71 & 648 \\
\hline 10 & Tetracontane & 39.78 & 562 \\
\hline 11 & 1-hexene, 6-phenyl-4-(1-phenylethoxy)- & 40.32 & 280 \\
\hline 12 & Sulfurous acid, butyl heptadecyl ester & 41.27 & 376 \\
\hline 13 & D-mannitol, 1-o-(22-hydroxydocosyl)- & 41.90 & 506 \\
\hline 14 & Cyclohexane, 1,1'-[1,2-bis(1,1-dimethylethyl)-1,2-ethanediyl]bis-, $\left(r^{*}, r^{*}\right)-($. & 42.47 & 306 \\
\hline 15 & Hexacosane & 42.94 & 366 \\
\hline 16 & Dichloroacetic acid, 2,2-dimethylpropyl ester & 44.89 & 198 \\
\hline
\end{tabular}

Table 2 Individual constituents present in the femoral gland secretion from the house gecko Hemidactylus flaviviridis

\begin{tabular}{c|l|c|c}
\multicolumn{1}{c|}{ Constituent } & $\begin{array}{c}\text { Retention time } \\
\text { (minutes) }\end{array}$ & $\begin{array}{c}\text { Molecular } \\
\text { weight }\end{array}$ \\
\hline Sl. No. & \multicolumn{1}{c}{ (1) } & 114 \\
\hline 2 & Oxirane, (2-methylbutyl)- & 21.77 & 128 \\
\hline 3 & 2-butene, 1-butoxy-, (e)- & 22.35 & 118 \\
\hline 4 & Cyclobutanecarboxylic acid chloride & 23.61 & 455 \\
\hline 5 & L-norleucine, n-ethoxycarbonyl-, octadecyl ester & 33.82 & 394 \\
\hline 6 & Dridecane, 2,2,4,10,12,12-hexamethyl-7-(3,5,5-trimethylhexyl)- & 34.05 & 188 \\
\hline 7 & Tritetracontane & 35.60 & 604 \\
\hline 8 & Dotriacontane & 37.06 & 450 \\
\hline 9 & Tridecane, 6-cyclohexyl- & 38.44 & 266 \\
\hline 10 & Pentacosane & 38.54 & 352 \\
\hline 11 & Sulfurous acid, butyl octadecyl ester & 39.79 & 390 \\
\hline 12 & Hentriacontane & 40.87 & 436 \\
\hline 13 & Meso-4,5-dicyclohexyl-2,7-dimethyloctan & 41.28 & 306 \\
\hline 14 & Eicosane & 41.89 & 282 \\
\hline 15 & Heptacosanoic acid, 25-methyl-, methyl ester & 42.96 & 438 \\
\hline 16 & Octatriacontane, 1,38-dibromo- & 43.48 & 690 \\
\hline 17 & Pentatriacontane & 44.36 & 492 \\
\hline 18 & Hexacosanol, acetate & 44.91 & 424 \\
\hline 19 & Sulfurous acid, butyl tetradecyl ester & 45.09 & 334 \\
\hline
\end{tabular}




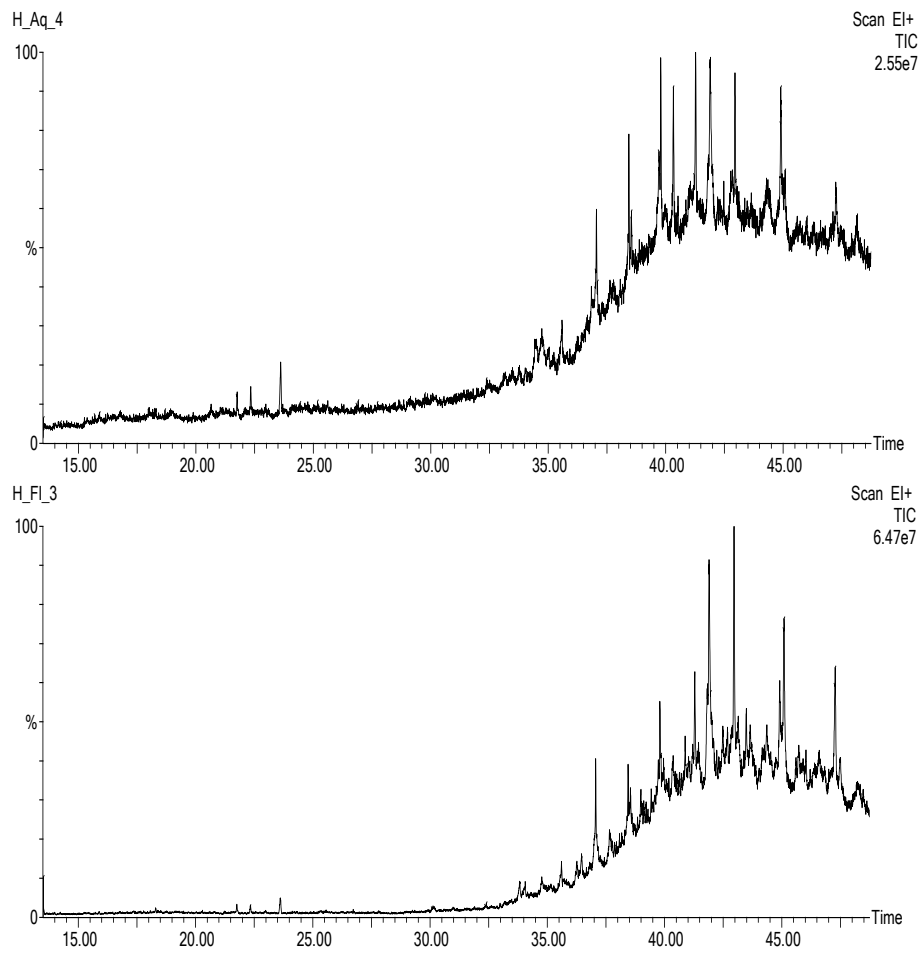

Figure 2 Total ion chromatogram of an extract of (A) Hemidactylus aquilonius and (B) Hemidactylus flaviviridis.

Overall, the present study revealed the presence of various type organic compounds in the femoral gland secretion of the house geckos, including alkanes (25\% in $H$. aquilonius versus $53 \%$ in $H$. flaviviridis), esters $(31 \%$ in $H$. aquilonius versus $21 \%$ in $H$. flaviviridis) and halides (6\% in H. aquilonius versus $11 \%$ in $H$. flaviviridis) as the major ones. Contents of alcohols $(19 \%$ in $H$. aquilonius versus $5 \%$ in $H$. flaviviridis) and carboxylic acids $(13 \%$ in $H$ aquilonius vs $10 \%$ in $H$. flaviviridis) were also moderate in the femoral gland secretion from both the species, whereas alkenes $(6 \%)$ were present only in the femoral gland secretion from $H$. aquilonius (figure 3 ).

A
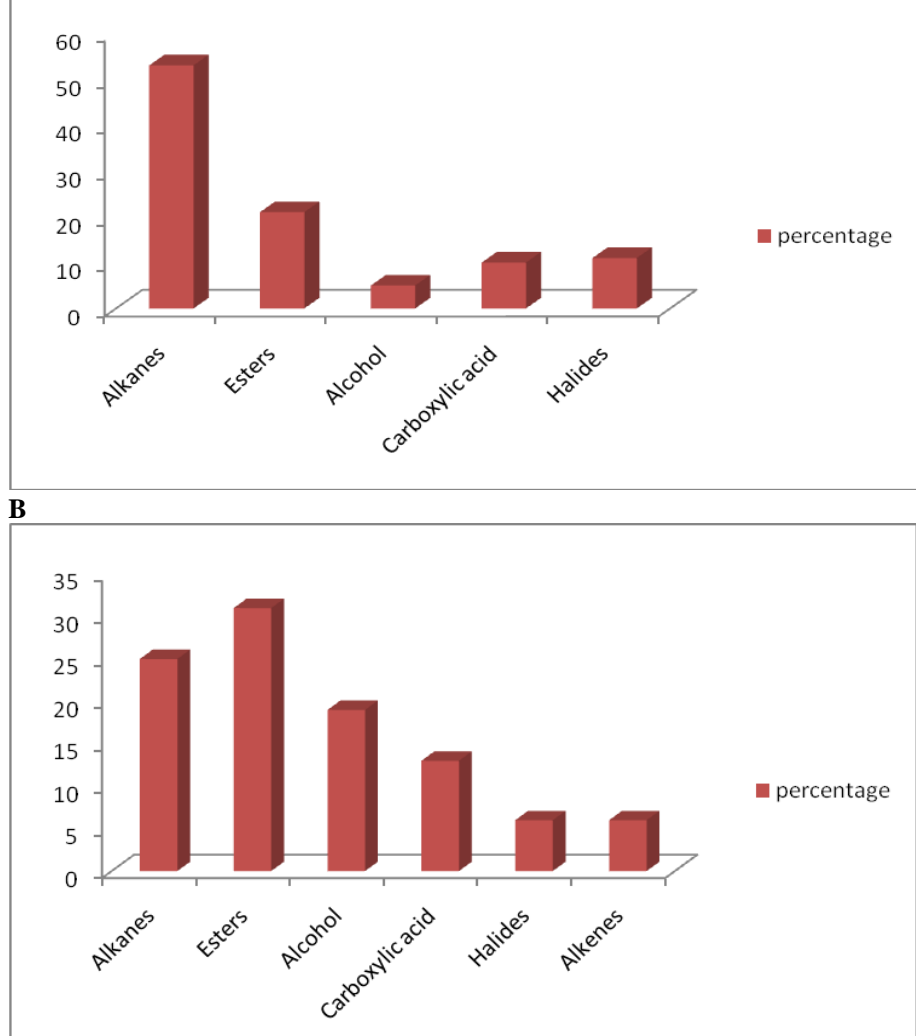

Figure 3 Major components present in the femoral gland secretion of (A) Hemidactylus aquilonius and (B) Hemidactylus flaviviridis.
Femoral gland secretion in lizards plays a major in chemoreception apart from reproduction. It is believed that the secretion of femoral gland is deposited in the home range of a male and functions to mark its territory. The secretion is odoriferous, and facilitates pairing of the sexes in the breeding season (Cole, 1966a). Differences between the chemical cues in various males of the same as well as different species could help females of the species to discriminate between them and thus affect their choice of males for mating. The secretion protruding from the pores in the breeding season also act as a tactile stimulus to females to quieten them in courtship or copulation (Noble and Bradley, 1933). In the present study, the secretions from femoral glands of $H$. aquilonius and $H$. flaviviridis were predominated by alkanes, esters, alcohols and carboxylic acids. Alberts et al. (1992) reported that in most cases such secretions are of lipid origin. However, in desert iguana Dipsosaurus dorsalis the main constituents of the femoral gland secretion were proteins and lipids. Volatile lipids are believed to act as olfactory cues for the detection of femoral secretions (Alberts, 1990). In other lizard species, these constituents belong to three main classes of alkanes, carboxylic acids, and steroids (Chauhan 1987; Alberts 1990; Alberts et al., 1992). A possible explanation of the differences in chemical composition of the secretions might be the consequence of different diets, or different available food sources in the island and in the mainland in regards to the habitat which the lizard species occupies. Also, such differences might simply result from genetic differences between populations and species. However, testing such hypothesis would require detailed behavioural study of the house geckos. In conclusion, this is the first report on the femoral gland secretion from the genus Hemidactylus in Assam, India.

Acknowledgements: The authors are thankful to Mr. Sumit Das and $\mathrm{Mr}$ Gyanendra Deka for their help in collection of specimen for the study. Technical support from IBT Hub, Arya Vidyapeeth College, Guwahati, Assam is also acknowledged thankfully.

\section{REFERENCES}

Alberts, A. C. (1990). Chemical properties of femoral gland secretions in the desert iguana, Dipsosaurus dorsalis. Journal of Chemical Ecology, 16(1), 13-25. https://doi.org/10.1007/BF01021264

Alberts, A. C. (1992). Constraints on the design of chemical communication systems in terrestrial vertebrates. The American Naturalist, 139, S62-S89. https://doi.org/10.1086/285305

Aragon, P., Lopez, P. \& Martin, J. (2001). Discrimination of femoral gland secretions from familiar and unfamiliar conspecifics by male Iberian rock-lizards, Lacerta monticola. Journal of Herpetology, 35(2), 346-350.

https://doi.org/10.2307/1566131

Chauhan, N. B. (1986). A preliminary report on the lipid components of pre-anal gland secretion of lizards Hemidactylus flaviviridis and Uromastyx hardwickii. The Journal of Animal Morphology and Physiology, 33, 73-76.

Cole, C.J. (1966). Femoral glands of the lizard, Crotaphytus collaris. Journal of Morphology, 118(1), 119-135. https://doi.org/10.1002/jmor.1051180108

Escobar, C. A., Labra, A. \& NIEMEYER, H. M. (2001). Chemical composition of precloacal secretions of Liolaemus lizards. Journal of Chemical Ecology, 27(8), 1677-1690.

https://doi.org/10.1023/A:1010470611061

Escobar, C. M., Escobar, C. A., Labra, A. \& NIEMEYER H. M. (2003) Chemical composition of precloacal secretions of two Liolaemus fabiani populations: are they different? Journal of Chemical Ecology, 29(3), 629-638. https://doi.org/10.1023/A:1022858919037

Khannoon, E.R.R. (2012). Secretions of pre-anal glands of house-dwelling geckos (Family: Gekkonidae) contain monoglycerides and 1,3-alkanediol. A comparative chemical ecology study. Biochemical Systematics and Ecology, 44, 341-346. https://doi.org/10.1016/i.bse.2012.06.024

Lopez, P. \& MARTIN, J. (2002). Chemical rival recognition decreases aggression levels in male Iberian wall lizards, Podarcis hispanica. Behavioral Ecology Sociobiology, 51(5), 461-465

https://doi.org/10.1007/s00265-001-0447-x

Lopez, P. \& Martin, J. (2005). Chemical compounds from femoral gland secretions of male Iberian Rock lizards, Lacerta monticolacyreni. Zeitschrift furNaturforschung C, Journal of Biosciences, 60(7-8), 632-636. https://doi.org/10.1515/znc-2005-7-820

Lopez, P. \& Martin, J. (2006). Lipids in the femoral gland secretions of male Schreiber's green lizards, Lacerta schreiberi. Zeitschrift fur Naturforschung $C$, Journal of Biosciences, 61(9-10), 763-768. https://doi.org/10.1515/znc-2006-9-1025 
Martin, J. \& Lopez, P. (2000). Chemoreception, symmetry and mate choice in lizards. Proceeding of Biological Sciences, 267(1450), 1265-1269.

https://doi.org/10.1098/rspb.2000.1137

Noble, G.K. \& BRADLEY, H.T. (1933). The mating behavior of Lizards; its

Bearing on the Theory of Sexual Selection. Annals of the New York Academy of Sciences, 35, 25-100.

https://doi.org/10.1111/j.1749-6632.1933.tb55365.x

Purkayastha, J., Das, M \& Sengupta, S. (2011). Urban herpetofauna: a case study in Guwahati City of Assam, India. Herpetology Notes, 4, 195-202.

Smith, M.A. (1935). The Fauna of British India, Including Ceylon and Burma. Reptilia and Amphibia(Vol. II, Sauria). London: Taylor \& Francis.

Weldon, P. J., Dunn JR, B. S., McDaniel, C. A. \& Werner, D. I. (1990). Lipids in the femoral gland secretions of the green Iguana (Iguana iguana). Comparative Biochemistry and Physiology Part B: Comparative Biochemistry, 95(3), 541-543. https://doi.org/10.1016/0305-0491(90)90017-N 